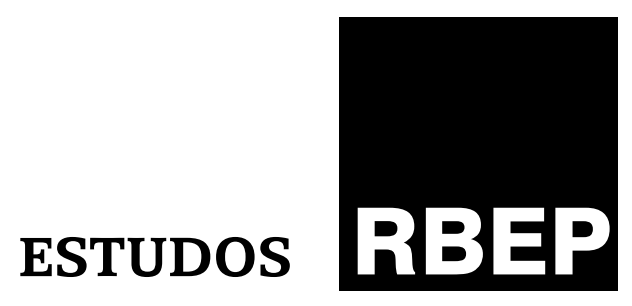

\title{
Políticas de material didático no Brasil: organização dos processos de escolha de livros didáticos em escolas públicas de educação básica
}

\author{
Luciana Bagolin Zambon \\ Eduardo Adolfo Terrazzan
}

\section{Resumo}

Apresenta os resultados de estudo sobre os processos de escolha de livros didáticos (LD), no âmbito do Programa Nacional do Livro Didático (PNLD), mediante o qual buscamos responder a seguinte questão: Como escolas de educação básica (EEB) organizam e desenvolvem ações para a escolha de LD? Para a coleta de informações, realizamos entrevistas com membros das equipes gestoras de 15 EEB. Pelas análises das entrevistas realizadas, podemos afirmar que: 1) a organização do processo de escolha de LD nas EEB foi desencadeada muito mais por ações desenvolvidas pelas editoras do que propriamente por orientações do Fundo Nacional de Desenvolvimento da Educação (FNDE); 2) no processo de escolha de LD, é bastante comum a realização de encontros breves durante o intervalo das aulas, no qual os professores costumam tomar suas decisões acerca da seleção dos livros; 3) as ações desenvolvidas nas EEB mobilizam todos os professores, mediante a realização de, ao menos, uma reunião, mas essas ações restringem-se à tarefa de escolha dos LD em cada área disciplinar, não havendo discussões mais amplas acerca das finalidades próprias do ensino médio, nem acerca do papel dos LD para tanto.

Palavras-chave: livro didático; Programa Nacional do Livro Didático; instituições de educação básica; ensino médio. 


\section{Abstract \\ Policies of didactic material in Brazil: organization of procedures for selection of textbooks in basic education public schools}

This article presents the results of a study on the process of choosing textbooks (LD), within the Brazilian National Textbook Program (PNLD), in order to answer the following question: How do Basic Education Schools (EEB) organize and develop actions to choose LD? To collect information, we interviewed members of the management team from 15 EEB. By analyzing the interviews, we can say that: (1) The organization of the process for choosing $L D$ in EEB was triggered by publishers actions, rather than the FNDE guidelines; (2) in the process of choosing $L D$ is quite common for the teachers to have short meetings during the break between classes, so that they can make decisions about the choice of $L D$; (3) the actions developed in EEB mobilize all teachers in at least one meeting, but these actions are restricted to the task of choosing the $L D$ for each subject area, with no further discussions about the specific aims of high school, or the role of $L D$.

Keywords: textbooks; Brazilian National Textbook Program; basic education schools; high school.

\section{Introdução}

Este artigo apresenta síntese comentada dos principais resultados de investigações realizadas no âmbito do projeto de pesquisa Inovações Educacionais e as Políticas Públicas de Avaliação e Melhoria da Educação no Brasil (Iepam), aprovado no Edital Capes/Inep/Secad nº 001/2008, do Programa Observatório da Educação da Coordenação de Aperfeiçoamento de Pessoal de Nível Superior (Capes). Buscamos, com esse projeto, compreender como algumas políticas educacionais - de avaliação da educação básica, de formação de professores e de materiais didáticos incidem em escolas públicas de educação básica e que implicações trazem para o trabalho escolar, em especial para o trabalho docente desenvolvido nessas escolas.

Partimos do pressuposto básico de que as orientações e as determinações presentes nas políticas educacionais se configuram como prescrições para o desenvolvimento das atividades cotidianas das instituições escolares. Nesse sentido, compreender as formas como essas políticas educacionais incidem no ambiente escolar permite estabelecer considerações fundamentais acerca da organização e do desenvolvimento do trabalho escolar realizado nas escolas.

De modo mais específico, este artigo se insere no conjunto das contribuições com os estudos e as discussões acerca das incidências 
dos programas de material didático do governo federal, em particular, do Programa Nacional do Livro Didático (PNLD), em escolas públicas de educação básica do Brasil.

Dentre os aspectos característicos do PNLD/Ministério da Educação (MEC) que evidenciam a grande relevância dos estudos sobre esse programa no contexto atual, convém destacar alguns: 1) a amplitude que os programas de material didático assumem na atualidade no Brasil, tornando o nosso País o maior comprador de livros didáticos do mundo; 2) a consolidação do PNLD como política de Estado (e não de governo), estabelecendo um mecanismo próprio de escolha dos livros pelos professores; 3) a presença de livros didáticos no cotidiano das escolas e das salas de aula do País, reafirmada a partir da consolidação do PNLD, de uma forma mais efetiva e intensa e com perspectivas de melhor utilização.

Na seção seguinte, apresentamos um breve histórico do PNLD, considerando como marco o ano de 1985, quando foi criado esse programa. ${ }^{1}$

\section{O Programa Nacional do Livro Didático (PNLD)}

Os atuais programas de material didático do governo federal, em particular o PNLD, têm a intenção de contribuir para a garantia de materiais didáticos de qualidade, disponíveis para subsidiar o desenvolvimento dos processos de ensino e de aprendizagem nas escolas, e são realizados com o intuito de dar conta de um dos aspectos que, desde a Constituição de 1988 (art. 208), constitui dever do Estado com a educação: "VII - atendimento ao educando, em todas as etapas da educação básica, por meio de programas suplementares de material didático-escolar, transporte, alimentação e assistência à saúde".

Assim sendo, compreendemos o PNLD como programa de distribuição gratuita de obras didáticas de forma sistemática e regular a todos os alunos (individualmente) das escolas de educação básica das redes escolares públicas do País e o consideramos como política de Estado, dado seu período de existência e sua permanência desde o ano de 1985, mantendo algumas das características iniciais do programa.

O PNLD foi criado por meio do Decreto $n^{\circ}$ 91.542, de 19 de agosto de 1985, em substituição ao programa anterior em vigor até então, denominado Programa do Livro Didático (PLID). O decreto de criação do PNLD previa, entre outros aspectos, a participação do professor na indicação das obras didáticas e a utilização do livro durável. Já na década de 1990, começam a ser projetados os primeiros passos para instituir um mecanismo de avaliação dos livros didáticos indicados pelos professores, medida que procurou colocar em cena a discussão sobre a qualidade dos livros, ausente no Decreto no 91.542.

Desse modo, em 1993 o MEC institui uma comissão de especialistas

${ }^{1}$ Uma descrição mais completa do histórico do PNLD pode ser encontrada em Zambon (2012) encarregada de avaliar a qualidade das dez obras mais solicitadas pelos professores em 1991, para as disciplinas de Português, Matemática, 
Ciências e Estudos Sociais, dirigidas aos anos iniciais do ensino fundamental. Iniciaram-se também, no âmbito dessa comissão, discussões sobre critérios para avaliação de livros didáticos. Como resultado desse trabalho, foi publicado em 1994 o documento "Definição de Critérios para Avaliação dos Livros Didáticos", focalizando aspectos tanto da produção física do livro quanto da formulação metodológica das obras.

Em 1996, é efetivamente iniciado o processo de avaliação pedagógica dos livros inscritos para o PNLD, sendo publicado o primeiro "Guia de Livros Didáticos" de $1^{\mathrm{a}}$ a $4^{\mathrm{a}}$ série do ensino fundamental.

Outro marco importante nesse período é o estabelecimento, a partir da Resolução nº 6, de julho de 1993, do Fundo Nacional de Desenvolvimento da Educação (FNDE), de recursos para a aquisição de livros didáticos para alunos das redes públicas de ensino fundamental, ficando assegurado um fluxo regular de verbas para a aquisição e distribuição dos livros.

Assim, a implementação de mecanismos de avaliação das obras inscritas no PNLD e a universalização da distribuição planejada de livros didáticos no ensino fundamental (mediante uma organização cíclica, instituída em 1996) marcam o estabelecimento de um conjunto de procedimentos para desenvolvimento do PNLD, o que permitiu sua consolidação como programa de distribuição de livros.

Já na década de 2000, assistimos a uma ampliação do PNLD, com a perspectiva de expandir a universalização da distribuição de livros para o ensino médio e para a modalidade Educação de Jovens e Adultos (EJA). Em 2003 é criado, a partir da Resolução CD/FNDE n 38, de 15 de outubro de 2003, o Programa Nacional do Livro para o Ensino Médio (PNLEM) e, em 2007, a partir da Resolução CD/FNDE nº 18, de 24 de abril de 2007, é criado o Programa Nacional do Livro Didático para a Alfabetização de Jovens e Adultos (PNLA).

A ampliação do programa do livro para o ensino médio pode ser entendida como parte de uma política mais ampla de expansão dessa etapa da escolaridade. Inicialmente, o PNLEM foi desenvolvido em caráter "experimental" no âmbito do que foi chamado de Projeto-Piloto (20052007). Em 2004, foram avaliadas obras de Português e Matemática, e, no ano seguinte, o programa atendeu alunos do ensino médio das Regiões Norte e Nordeste do Brasil, distribuindo os livros recomendados. No ano de 2006, os livros dessas duas disciplinas foram distribuídos aos demais estudantes de ensino médio e, em 2007, foram avaliados e distribuídos os de Biologia para escolas públicas de ensino médio de todo o País. A universalização da distribuição das obras didáticas de Português, Matemática, Física, Biologia, Química, História e Geografia ocorreu na edição de 2008 do PNLEM, com distribuição dos livros para as escolas no ano seguinte.

Em 2009, a partir da Resolução CD/FNDE n 60, de 20 de novembro 2009, o PNLEM e o PNLA foram incorporados ao Programa Nacional do Livro Didático, que passou a ser denominado de PNLD EJA e PNLD para Educação Básica. 
Já em 2010 foi publicado o Decreto $n^{0} 7.084$, de 27 de janeiro de 2010, que regulamentou a avaliação e a distribuição de materiais didáticos para toda a educação básica, garantindo, assim, a regularidade da distribuição de livros. A partir desse mesmo decreto ficam instituídos dois grandes programas: Programa Nacional do Livro Didático para a Educação Básica e Programa Nacional Biblioteca na Escola (PNBE). ${ }^{2}$

O PNLD mantém um processo cíclico de operacionalização, de modo que a avaliação, a escolha e a aquisição das obras ocorrem de forma periódica. São garantidos, portanto, ciclos regulares trienais alternados, intercalando, a cada ano, o atendimento aos seguintes níveis de ensino: $1^{\circ}$ ao $5^{\circ}$ ano do ensino fundamental, $6^{\circ}$ ao $9^{\circ}$ ano do ensino fundamental e ensino médio.

Em termos de procedimentos envolvidos na operacionalização do PNLD, podemos distinguir, atualmente, três etapas: na primeira ocorre a avaliação de obras didáticas, por componente curricular dos níveis de ensino fundamental e médio. A avaliação é realizada por equipes de especialistas, consultores ad hoc, a partir das obras inscritas em atendimento a edital específico do programa. Resulta desse processo de avaliação a recomendação de um conjunto de obras para cada componente curricular, as quais atendem ao mínimo de qualidade estabelecido no edital. Como produto final dessa etapa, cada equipe elabora um guia de livro didático, contendo resenhas avaliativas das obras recomendadas.

Na segunda etapa, acontece a escolha dos livros didáticos pelos professores das escolas. Para o desenvolvimento dessa fase, espera-se a atuação efetiva das secretarias estaduais e municipais de educação, bem como das equipes diretivas das escolas. Mecanismos devem ser estabelecidos para esse processo, tendo por base as resenhas dos guias de livros didáticos elaborados para cada componente curricular e a participação coletiva dos professores de cada escola. Espera-se um processo em que o conjunto de docentes de cada componente curricular discuta e decida sobre as obras didáticas que serão selecionadas, dentre aquelas recomendadas na $1^{\mathrm{a}}$ etapa e constantes do guia. Espera-se que todos os professores tenham acesso ao guia, bem como a exemplares dos volumes das obras didáticas recomendadas. Ao final, deve resultar uma listagem de indicações dos livros mais adequados para o desenvolvimento das atividades previstas em cada componente curricular. Essas listagens são encaminhadas ao MEC por um responsável na escola que tem acesso à senha, para posterior recebimento das obras indicadas.

Na terceira etapa, ocorre o envio das obras didáticas escolhidas pelos professores às escolas. Espera-se, nessa última fase, que os livros selecionados cheguem às escolas em tempo hábil para o início das atividades letivas previstas e na quantidade correta e que só em último

${ }^{2}$ O PNBE foi instituído pela Portaria ${ }^{\circ} 584$, de 28 de abril de 1997, com o objetivo de adquirir obras de referência, de literatura e de pesquisa, bem como outros materiais de apoio à prática educativa. caso sejam enviadas obras não escolhidas, na medida em que se considera a segunda etapa como a fase em que, fundamentalmente, os professores têm uma participação direta no processo como um todo.

A pesquisa que está aqui sendo apresentada focalizou a segunda etapa de operacionalização do programa, envolvendo os processos de 
escolha dos livros organizados em escolas de educação básica, no âmbito do PNLD 2012 Ensino Médio.

No campo acadêmico, é perceptível a crescente preocupação de pesquisadores com a temática do livro didático nos últimos anos, o que se justifica, em parte, pela consolidação e pelo crescimento do PNLD nas últimas décadas. Nesse sentido, apresentamos na seção seguinte breve relato dos resultados obtidos em trabalho de revisão de literatura em teses/dissertações da área de pesquisa em educação em Ciências e em periódicos acadêmico-científicos, também dessa área, sobre essa temática.

\section{Pesquisas acadêmico-científicas sobre livro didático no Brasil}

Em trabalho recente de revisão de literatura sobre o tema "livro didático" (Zambon, 2012), realizado em teses/dissertações e em artigos publicados em periódicos acadêmico-científicos da área de pesquisa em educação em Ciências, constatamos que são raríssimos os estudos nessa área que problematizam aspectos relacionados à utilização do livro didático por professores e alunos em sala de aula ou que abordam os processos de seleção dessas obras organizados em escolas.

Nesse trabalho de revisão, identificamos 127 teses/dissertações da área de pesquisa em educação em Ciências sobre a temática "livro didático", disponibilizadas no banco de dados do Centro de Documentação em Ensino de Ciências da Universidade Estadual de Campinas (Cedoc/ Unicamp), período 1996 a 2008, e no Banco de Teses da Capes, período de 2007 a 2010, e 46 artigos publicados em 9 periódicos acadêmicocientíficos também dessa área.

Constatamos, a partir desse levantamento, que a grande maioria das teses/dissertações e dos artigos identificados se refere à análise do conteúdo do livro didático (investigando, por exemplo, concepções de natureza por ele veiculadas, formas de abordagem de algum conteúdo conceitual, formas de utilização de imagens, etc.) e à da utilização de recursos e estratégias didáticas nessas obras. No entanto, as investigações que se ocupam da análise do uso de livros didáticos em sala de aula e do seu processo de escolha e avaliação são muito raras.

Dentre as pesquisas que investigam a escolha de obras, Tolentino Neto (2003), em estudo sobre a seleção do livro de Ciências por professores dos anos iniciais, constatou a diversidade de critérios utilizados e a de condições para as escolhas, a pouca utilização do Guia do Livro Didático e o desconhecimento de importantes etapas do programa.

Cassab e Martins (2008) investigam os sentidos que professores de Ciências atribuem ao livro didático em um contexto de escolha do material. A discussão realizada pelas autoras gira em torno das imagens de aluno, de ensino e de ensino de Ciências na significação do livro didático, da linguagem e de seus aspectos visuais. As autoras afirmam que os critérios utilizados por professores na seleção refletem os significados que eles atribuem a esses aspectos. 
Lima e Silva (2010), por sua vez, investigam os critérios utilizados por professores de Química na escolha do livro didático e apontam que os mais considerados são: a linguagem, a diagramação, a contextualização, as experimentações e o tipo de abordagem adotada para o tratamento dos conteúdos.

Essas investigações tomaram por objeto a escolha de livros pelo professor, analisando os critérios e procedimentos utilizados para essa seleção. Não identificamos, entretanto, investigações que se ocuparam dos mecanismos adotados pelas equipes gestoras de escolas para organizar os processos de escolha de livros, no âmbito do PNLD.

Nesse sentido, considerando essa lacuna no campo de pesquisas da área, desenvolvemos este estudo com o objetivo de buscar responder a seguinte questão: Como as equipes gestoras de escolas públicas de educação básica organizam e desenvolvem ações para a escolha de livros didáticos no âmbito do PNLD 2012 Ensino Médio?

\section{Procedimentos metodológicos utilizados para desenvolvimento deste estudo}

Para responder a questão de pesquisa proposta, utilizamos como fonte de informações, na modalidade sujeito, os membros das equipes gestoras de escolas públicas de educação básica da cidade de Santa Maria/RS e como instrumento para coleta dessas informações, a entrevista estruturada, mediante roteiro específico (ver Apêndice).

O roteiro utilizado nessas entrevistas foi organizado em quatro blocos: 1) organização de mecanismos para o processo de escolha de livros didáticos; 2) desenvolvimento das reuniões para essa seleção; 3) entrega dos livros na escola; 4) formas de organização do processo de escolha no âmbito do PNLD 2012/Ensino Médio.

O universo da pesquisa envolveu todas as 27 escolas públicas de educação básica da cidade de Santa Maria/RS que possuem o ensino médio como etapa de escolaridade, das quais 24 são da rede pública estadual e 3 da rede pública federal.

Tendo em vista a seleção de livros didáticos prevista para o ano de 2011, no âmbito do PNLD 2012/Ensino Médio, contatamos, no início do ano letivo, as equipes gestoras de todas as 27 escolas, com o intuito de informar os objetivos de nossa pesquisa e questionar sobre a possibilidade de realizá-la com essas equipes.

O contato com membros das equipes gestoras ocorreu, inicialmente, por ligação telefônica, na qual agendamos contato pessoal para esclarecimentos ou, em alguns casos, para realização da própria entrevista.

Recebemos resposta negativa para fazer a entrevista das equipes gestoras de 12 escolas, sendo que 3 delas informaram que não têm recebido retornos das pesquisas feitas em sua escola, o que tem desmotivado a participação em novos estudos. As demais escolas 
utilizaram como justificativa principal a falta de tempo para realização da referida entrevista.

Desse modo, a amostra para essa pesquisa envolveu um total de 15 membros das coordenações pedagógicas (CP), que forneceram informações mediante entrevista com cada um deles.

Para proceder ao tratamento e apreciação das informações coletadas, utilizamos a técnica da categorização temática (Gibbs, 2009) e estabelecemos categorias de análise a posteriori, ou seja, como resultado de várias leituras das informações, para cada critério de análise definido previamente - na próxima seção, apresentamos e discutimos os principais resultados obtidos nessa análise. É importante notar que algumas das categorias e subcategorias definidas e utilizadas para construção e avaliação dos resultados não são excludentes; por isso, em alguns casos o número de ocorrência não corresponde ao de coordenadores pedagógicos entrevistados.

\section{Constituição e discussão de resultados}

Procuramos entender, primeiramente, como começou a mobilização nas escolas para iniciar o processo de escolha de livros didáticos, no âmbito do PNLD 2012. Pelas informações obtidas, percebemos que o envio de cópias das obras didáticas pelas editoras "disparou" esse processo, e o fato de o Guia de Livros Didáticos estar disponível na internet não teve efeito, pois não há nenhum indicador de que professores ou equipe gestora o consultaram antes de as editoras enviarem as obras. Parece ser, portanto, a chegada dos livros na escola que faz com que a gestão perceba que precisa agilizar o processo, distribuindo os materiais, criando mecanismos e organizando espaços para a escolha dos livros.

Ainda em relação ao envio das obras aprovadas para as escolas, podemos afirmar que algumas editoras continuam realizando a divulgação diretamente nas instituições de educação básica, durante o período destinado ao processo de escolha. Isso ficou evidenciado tanto nas falas de muitas coordenadoras como pelo fato de, durante as visitas às escolas para realizar a pesquisa, termos encontrado em algumas delas muitos representantes de editoras. Vale lembrar que essa ação está proibida desde a publicação da Portaria Normativa n ${ }^{0} 7$, de 2007, que dispõe sobre as normas de conduta no âmbito da execução dos Programas do Livro, em especial, aquela que proíbe a realização da divulgação das obras pessoalmente nas escolas, conforme item VIII, $\S 2^{\circ}$, art. $3^{\circ}$.

Além disso, percebemos que o tratamento dado pelas editoras às escolas, em relação à divulgação das obras, é diferente quando se trata de instituições maiores (maior número de alunos e professores) e de menores. Isso pode ser evidenciado na fala de muitas coordenadoras pedagógicas (CP) e, em especial, nos dois depoimentos abaixo:

[...] a nossa é uma das maiores escolas de ensino médio e ela é muito visitada pelos representantes, eles procuram bastante a escola e eles 
começaram a trazer o material [...]. A gente percebe que eles têm toda uma atenção com a nossa escola, até pelo número de alunos que a escola tem, né? [...] E nós ouvimos aqui na sala dos professores com relação a outras escolas 'ah, lá no outro colégio não chegou quase nada'. (CP 18).

[...] eles [representantes de editoras] mandam o material via correio, né? Aqui não chegou nenhum vendedor ainda das editoras (fala rindo), acho que o acesso é difícil. (CP 21).

A primeira fala é da coordenação pedagógica de uma das maiores escolas estaduais que possuem ensino médio na região investigada e evidencia a presença de representantes de editoras e o interesse delas em divulgar as obras nesta e em outras escolas com grande número de alunos. O trecho da fala "ah, lá no outro colégio não chegou quase nada", que a coordenadora disse ouvir dos professores, mostra que as demais escolas não tiveram o mesmo tratamento.

A segunda fala, por outro lado, é da coordenação pedagógica de uma escola estadual que funciona junto ao Centro de Atendimento SócioEducativo (Case) e atende a um número muito pequeno de alunos. Em tom de riso, a professora afirma que nenhum representante de editora esteve na escola e, em outros momentos, relata que chegaram poucas obras, evidenciando que, de fato, poucas editoras enviaram livros para essa instituição de ensino.

Muitas editoras preocupam-se em enviar cópias nominais de livros para todos os professores - ao invés de única cópia para toda a escola -, o que é interessante, pois agiliza o processo de análise dos livros, permitindo que os professores tenham acesso às obras e minimizando dificuldades que poderiam advir da necessidade de vários docentes olharem única cópia. Porém, isso teve consequências no processo de escolha dos livros, como pode ser percebido nos trechos selecionados abaixo:

Alguns [representantes], por exemplo, a \{nome da editora\}, vem nominal, cada professor recebe no seu nome, por isso que a maioria escolhe a \{nome da editora\}, porque já recebe bem personalizado. Mas as outras [editoras] vêm e tem gente que opta por outras editoras [...]. (CP 04).

[...] tem um trabalho de determinadas editoras né que ele se sobressai positivamente, até porque o representante é antigo, ele já conhece os professores [...] e o atendimento personalizado, quando eles entregam o material para o colega, ele já explica né, enquanto que outros apenas deixam aqui, e aí fica fácil pro professor, né. (CP 18).

Essas duas falas mostram que a forma como as editoras fazem a divulgação das obras aprovadas pode influenciar na decisão sobre a escolha dos professores, reafirmando a percepção de que as editoras tiveram um peso grande no processo de decisão sobre os livros, realizada no âmbito do PNLD 2012/Ensino Médio, na região estudada. Afinal, quando as possibilidades de realizar uma análise mais aprofundada dos livros são dificultadas, são esses aspectos, como a explicação/argumentação do representante da editora (propaganda, em outros termos), que acabam influenciando na decisão sobre a escolha. 
Depois que as escolas começam a receber os livros, inicia-se a mobilização para o processo de seleção. Quanto aos mecanismos para organização e desenvolvimento desse processo, percebemos que todas as escolas investigadas utilizaram pelo menos uma reunião pedagógica na qual a escolha de livros foi assumida como ponto de pauta. Em cinco delas aconteceu apenas uma reunião, na qual todos os professores estiveram juntos, com a finalidade única de compartilhar informações gerais sobre o PNLD e/ou sobre o processo interno de escolha de livros organizado pela escola. Essas informações, em geral, se reduzem a comunicar sobre os livros que chegaram e sobre o prazo para registro da seleção. Nesses casos, a escolha propriamente dita de livros aconteceu individualmente ou em encontros organizados pelos próprios professores de uma mesma área disciplinar, em geral no período de intervalo (recreio), na sala de professores.

Em oito escolas, as reuniões pedagógicas foram utilizadas para realizar, efetivamente, a análise e escolha de livros por professores reunidos em grupos por área disciplinar, como pode ser visto nos depoimentos abaixo:

[...] nós começamos utilizar as reuniões pedagógicas. Na reunião pedagógica aí os professores se reúnem por disciplina, ai vão estudando, discutindo os livros, até chegar o dia da escolha. Nós estamos, agora esta semana, vai ser a quarta reunião que a gente fica em cima do trabalho dos livros. (CP 11).

Então, eles são convocados, numa quarta-feira, que é o dia que a gente já tem as reuniões [pedagógicas] pré-agendadas. Eles apreciam os livros e aí é aquele "auê" de professores apreciando os livros [...]. (CP 04).

Percebemos, ainda, que é bastante comum, no processo de escolha de livros, a realização de encontros na sala de professores, durante o intervalo, reunindo os docentes de mesma área disciplinar que lecionam naquele dia. Parece ser, inclusive, nesses encontros breves que a maioria dos professores troca informações e toma decisões acerca dos livros didáticos, conforme depoimentos das coordenadoras pedagógicas.

Chama a atenção, também, o fato de que apenas quatro escolas utilizaram reunião pedagógica com o intuito de compartilhar os resultados da escolha de livros. Esse tipo de reunião seria uma oportunidade para que todos os professores trocassem informações sobre as justificativas para sua escolha, garantindo a transparência no processo de seleção de livros, e, ao mesmo tempo, discutissem aspectos mais amplos, de modo que o trabalho escolar fosse realizado de forma coerente, no sentido de que todos os professores, independentemente da área disciplinar, buscassem atender finalidades comuns da escola, expressas em seu projeto pedagógico.

Em relação aos materiais utilizados pelos professores para realizar a escolha dos livros didáticos, constatamos que na maioria das escolas (60\%) os docentes analisaram apenas os livros recebidos para fazer a seleção, conforme depoimentos das coordenadoras. Os trechos abaixo são representativos dessa categoria: 
(...) [os professores] deveriam analisar aquelas [obras] que eles tinham manuseado, isso que nós fizemos e reforçamos. (CP 01).

É que os guias dizem como os livros estão organizados, então vale mais a pena tu olhar o livro. (CP 15).

Só com os livros que chegam. É o que a gente pode manusear, né? Como é que tu vai escolher uma coisa que tu não tem como manusear? [Olhar o Guia] não é a mesma coisa que tu pegar o livro e olhar, né? (CP 25).

As demais coordenadoras (40\%) afirmaram que, além dos livros recebidos, os professores também consultaram o Guia. Porém, temos de observar que realizamos entrevistas com a coordenação pedagógica entre os meses de maio e junho de 2011, durante o período de escolha dos livros didáticos, no âmbito do PNLD 2012. Assim, quando fizemos as entrevistas, muitas escolas não tinham recebido ainda a cópia impressa do Guia (obtida somente no dia 31 de maio de 2011, portanto, 12 dias antes de encerrar o processo). Por isso, muitas coordenadoras, no momento da entrevista, nem sabiam do que se tratava. Nesses casos, aproveitamos a oportunidade para explicar que o Guia de Livros Didáticos estava disponível no site do FNDE e continha os critérios de avaliação e resenha das obras aprovadas, podendo servir como importante instrumento de apoio para a escolha dos livros. Assim, em três das seis respostas classificadas nessa categoria, as coordenadoras afirmaram que iriam informar os professores sobre o Guia e solicitar que ele fosse analisado. Portanto, o que temos nas respostas dessas coordenadoras é a manifestação de intenção de informar os professores sobre o Guia, e não a utilização, propriamente, por eles.

Em outra resposta, dentre essas seis, uma coordenadora afirmou que o Guia é analisado, mas as obras não são escolhidas caso o próprio livro não seja manuseado:

Sim, [os professores leem] a resenha, mas até hoje eu não vi a gente aqui escolher um livro que não estivesse o livro pra eles estudarem, dar uma olhada. (CP 11).

Tudo isso indica o peso que as editoras tiveram nesse processo de seleção dos livros no contexto investigado, chegando ao limite de o livro didático que não foi recebido na escola ter uma chance reduzida de ser escolhido.

Quanto aos espaços e tempos utilizados pelo professor para análise dos livros didáticos, em três escolas a sala de reuniões constituiu o local principal e, em outras quatro, a sala de professores, durante o intervalo de tempo em que o docente costuma ocupar esse espaço, ou seja, o intervalo escolar (recreio) ou o tempo livre em que está fora de sala de aula, mas aguardando o próximo período. Em dois casos, a biblioteca foi utilizada como espaço para análise dos livros, pois era o único local de que a escola dispunha para armazenar as obras enviadas pelas editoras.

A categoria mais recorrente (53\%), porém, foi a utilização da residência do professor como espaço para análise dos livros. Como não 
há necessidade de ele permanecer na escola no período destinado ao planejamento (horas-atividade) e não há uma contabilidade de quantas horas o professor utilizou em casa para análise dos livros, não temos como saber se esses docentes utilizaram seu tempo de trabalho (4h de horas-atividade) ou seu tempo pessoal.

Entendemos que o problema não é a utilização da residência em si como espaço para análise dos livros, desde que esteja sendo utilizado o período que o professor possui para realizar seu planejamento. Porém, sabemos que esse período tem sido insuficiente para ele realizar todas as tarefas que compõem a docência, a qual não se restringe ao trabalho em sala de aula, em especial nesse momento em que precisa decidir sobre o livro que adotará pelos próximos três anos.

Outro problema é o fato de os professores, em geral, terem banalizado essa situação, incorporando-a como sendo própria da profissão docente, ou seja, aceitando como natural o fato de ele precisar utilizar seu período de descanso e lazer para planejar, corrigir provas, examinar livros, etc.

Analisamos também o envolvimento de instâncias políticoadministrativas da secretaria estadual de educação com os processos de escolha de livros didáticos. Pelas informações coletadas nas escolas e no setor pedagógico da própria secretaria, podemos afirmar que a participação dessas instâncias nesse processo foi pífia, ficando reduzida ao repasse de e-mail com informações relativas à parte operacional da escolha. Não houve, portanto, nenhum tipo de contato, pelas informações obtidas, no sentido de orientar as escolas sobre aspectos pedagógicos da escolha dos livros.

\section{Conclusões}

Em relação à organização da escolha dos livros, podemos afirmar que esse processo se iniciou efetivamente a partir da chegada das obras na escola, as quais, em alguns casos, foram entregues pessoalmente por representantes de editoras, usualmente daquelas já tradicionais e com forte presença no meio escolar.

Em termos de ações que são desenvolvidas pelo FNDE e pela secretaria de educação do Estado, podemos dizer resumidamente que aquele publica o Guia de Livros Didáticos e envia para as escolas cópia impressa desse material, bem como de documentos (carta-circular), informando senha e login para efetivação da escolha das obras, solicitando análise do Guia de Livros Didáticos, estabelecendo prazo para realização dessa seleção, fornecendo orientações para o registro da escolha das obras, etc. Já a secretaria de educação do Estado limitou-se ao envio de mensagem de e-mail com informações técnicas sobre o processo de escolha, basicamente repetindo as informações do FNDE, o que caracteriza uma participação irrisória nesse processo.

Oficialmente, são essas ações que dão início ao processo de escolha de livros, no âmbito do PNLD. Porém, pelas informações coletadas, 
percebemos que isso foi insuficiente para mobilizar a gestão das escolas investigadas.

O que pudemos perceber é que as escolas começaram a se mobilizar, efetivamente, para organização do processo de escolha, na medida em que consideravam a quantidade de livros recebidos suficiente para iniciar sua análise, usualmente utilizando-se de uma avaliação muito subjetiva em relação a esse número suficiente de livros. Um fator que pareceu ser considerado, também, foi o espaço físico que essas obras passaram a ocupar na escola, o qual já é reduzido.

Outro aspecto que preocupa bastante é a falta de conhecimentos sobre o próprio programa por parte das equipes gestoras das escolas: algumas coordenadoras, por exemplo, demonstraram total desconhecimento sobre a existência do Guia de Livros Didáticos até a realização de nossa entrevista. Um agravante, nesse sentido, consiste no fato de que, sem conhecer o Guia, as equipes gestoras também não sabiam quantas obras enviadas pelas editoras poderiam chegar para análise, o que causou uma restrição para o processo de tomada de decisão, já que somente algumas obras passaram pela análise dos professores.

Assim sendo, pode-se dizer que as escolas ficaram sujeitas aos procedimentos utilizados pelas editoras para divulgação dos livros. Constatamos, por exemplo, que muitas editoras possuem uma relação bem próxima com os professores e, na medida em que elas utilizam fortes estratégias de marketing, acabam tendo grande poder de convencimento para a realização da escolha.

De modo geral, podemos caracterizar a situação analisada pelos seguintes aspectos: 1) muitas escolas não tiveram acesso ao Guia em tempo suficiente para análise (conforme relato das coordenadoras pedagógicas); 2) muitos professores preferiram realizar análise direta dos livros, em detrimento de uma análise preliminar, a partir do Guia; 3) nem todos os livros aprovados chegaram à escola, o que acarreta total desconhecimento de algumas dessas obras por parte dos professores; 4) no caso estudado, o tempo entre o recebimento das obras enviadas pelas editoras e o encerramento do prazo para indicação ao MEC foi muito curto. Tendo em vista esses aspectos, a alternativa que pareceu restar aos professores foi a escolha do livro da editora que, além de enviá-lo à escola, conversou com o professor, apresentou e explicou a natureza do livro ou, nas palavras dos gestores investigados neste trabalho, daquela editora que ofereceu um atendimento mais "personalizado"!

[...] a maioria escolhe o livro da \{nome da editora\}, porque já recebe bem personalizado. (CP 04).

[Algumas editoras têm] o atendimento personalizado. Quando eles entregam o material para o colega [professor], ele já explica, né? (CP 11).

Por isso, é inegável o grande peso que as editoras tiveram nos processos de decisão sobre a escolha dos livros didáticos, seja pelo envio efetivo das obras às escolas, fazendo iniciar o processo de seleção, seja pela forma como divulgam os livros e se relacionam com as escolas e, individualmente, com os professores. 
Podemos concluir, então, que a execução do PNLD e a organização do processo de escolha de livros didáticos nas escolas têm sido desencadeadas muito mais por ações desenvolvidas pelas editoras do que propriamente por orientações do FNDE/MEC ou das instâncias político-administrativas da secretaria estadual de educação.

Concluímos também que, no processo de escolha de livros didáticos, é bastante comum a realização de encontros breves na sala de professores e/ou durante o intervalo das aulas, em que os docentes costumam tomar suas decisões de caráter coletivo acerca dos livros a serem escolhidos. Para esse tipo de encontro, porém, espera-se que haja possibilidades de diálogo e de uma grande interação entre os professores. Nesse sentido, pode-se dizer que o procedimento de utilização da sala de professores durante o recreio como espaço único ou principal para discussão sobre os livros a serem escolhidos é extremamente inapropriado, pois normalmente há muito barulho, os professores estão no seu momento de descanso e a duração do intervalo é muito pequena (geralmente de 15 minutos, nas escolas da região investigada).

Podemos dizer ainda que as ações desenvolvidas nas escolas, relativas à sua participação no PNLD, mobilizam todos os professores, mediante a realização de, ao menos, uma reunião coletiva para todo o processo, mas essas ações restringem-se exclusivamente à tarefa de escolha dos livros didáticos em cada área disciplinar, não havendo discussões mais amplas acerca das finalidades próprias do ensino médio como etapa final da escolaridade básica no Brasil, nem acerca do papel dos livros didáticos para tanto.

Por fim, é espantoso afirmar que a citação abaixo, datada de 1987, permaneça atual em seus apontamentos, quando considerados os resultados obtidos em nossa investigação. Nesta citação, Lajolo, revisitando o tema "livro didático", elenca uma série de exigências que indicam as deficiências que ainda podiam ser apontadas na época, no contexto de criação do PNLD. A autora exigia, dentre outros aspectos:

1) que a escolha dos livros didáticos não se faça nem em cima da hora, nem em abstrato; que o Estado garanta que todo professor tenha acesso a todos os livros que constituem o acervo dentre o qual serão escolhidos os livros a serem adotados;

2) [que] a divulgação, com antecedência de muitas semanas do prazo final para o resultado da seleção; que se assegure, (...) tempo suficiente, dentro das horas pelas quais o Estado lhe paga para, em conjunto com seus colegas, efetuar a seleção; (...)

3) que o Estado não deixe em mãos de cada editora a tarefa de encaminhar aos professores os exemplares de seus livros que serão objeto da seleção. (...) a não mediação do Estado acaba favorecendo as editoras maiores, que dispõem de cadastros mais gordos e setores de divulgação mais ágeis;

4) que o Estado assuma a obrigação de garantir à sociedade que a seleção dos livros, em cuja compra se investe tanto de nossos suados impostos, seja feita com seriedade e competência. (Lajolo, 1987, p. 3-4, grifos da autora). 
Infelizmente, os resultados que obtivemos em nossa investigação indicam que, na prática, muitos desses aspectos ainda não foram efetivamente contemplados no âmbito da execução do PNLD em escolas públicas de educação básica.

\section{Referências bibliográficas}

BRASIL. Ministério da Educação (MEC). Secretaria de Educação Básica (SEB). Guia de livros didáticos: PNLD 2012. Brasília, 2011. Disponível em: <http://www.fnde.gov.br/programas/livro-didatico/guia-do-livro/ item/2988-guia-pnld-2012-ensino-m\%C3\%A9dio > .

CASSAB, M.; MARTINS, I. Significações de professores de ciências a respeito do livro didático. Ensaio: Pesquisa em Educação em Ciências, Belo Horizonte, v. 10, n. 1, p. 1-28, 2008.

GIBBS, Graham. Análise de dados qualitativos. Porto Alegre: Artmed, 2009.

LIMA, Maria E. C. de C.; SILVA, Penha S. Critérios que professores de Química apontam como orientadores da escolha do livro didático. Ensaio: Pesquisa em Educação em Ciências, Belo Horizonte, v. 12, n. 2, p. 121-136, 2010.

TOLENTINO NETO, Luiz C. B. de. O processo de escolha do livro didático de Ciências por professores de $1^{a}$ a $4^{a}$ séries. 2003. Dissertação (Mestrado em Educação) - Universidade de São Paulo. 2003.

LAJOLO, Marisa. O livro didático: velho tema, revisitado. Em Aberto, Brasília, v. 6, n. 35, p. 1-9, jul./set. 1987.

ZAMBON, Luciana B. Seleção e utilização de livros didáticos de Física em Escolas de Educação Básica. 2012. 279 p. Dissertação (Mestrado em Educação) - Universidade Federal de Santa Maria. 2012

Luciana Bagolin Zambon é doutoranda em Educação na Universidade Federal de Santa Maria (UFSM), Santa Maria, Rio Grande do Sul, Brasil. luzambon@gmail.com

Eduardo Adolfo Terrazzan, doutor em Educação pela Universidade de São Paulo (USP), é professor associado do Departamento de Metodologia do 
Ensino do Centro de Educação da UFSM (Núcleo de Estudos em Educação, Ciência e Cultura e Programa de Pós-Graduação em Educação), Santa Maria, Rio Grande do Sul, Brasil.

eduterranec@ymail.com

Recebido em 3 de setembro de 2012.

Aprovado em $1^{\circ}$ de maio de 2013. 
ANEXO: Roteiro de Entrevista - Coordenação Pedagógica

\begin{tabular}{|l|l|}
\hline \multirow{2}{*}{ Escola } & \multicolumn{2}{|l|}{ Código } \\
\cline { 2 - 3 } & Nome \\
\hline Entrevistador(a) & Nome \\
\hline \multirow{2}{*}{ Entrevistado(a) } & Nome \\
\cline { 2 - 3 } & Função \\
\hline
\end{tabular}

\begin{tabular}{|l|}
\hline Local da entrevista \\
\hline Data \\
\hline Dia da Semana \\
\hline Hora de Início \\
\hline Hora de Término \\
\hline
\end{tabular}

Estamos investigando as possíveis implicações do Programa Nacional do Livro Didático (PNLD) nas escolas públicas de educação básica. Para tanto, gostaríamos de saber, inicialmente, como ocorre o processo de escolha do livro didático no âmbito desse programa, na cidade de Santa Maria/RS.

\section{Organização dos mecanismos/reuniões para o processo de escolha}

- Você poderia relatar como ocorrem os processos de escolha de livros didáticos no âmbito do PNLD nesta escola?

- Como são organizados esses processos nesta escola? (Quem organiza? Como é a participação dos professores?)

- Que mecanismos foram adotados? (Foram organizadas reuniões?)

- Houve reuniões específicas para cada área disciplinar? Quantas?

- Em que horário elas aconteceram? Foram utilizadas reuniões pedagógicas regulares para isso?

- Em particular, que ações a escola organizou para realizar o processo de escolha de livros didáticos no âmbito do PNLEM/2007? Como foi o processo de escolha de livros didáticos de Física no âmbito do PNLEM/2007?

- Qual o envolvimento da secretaria estadual de educação na organização dos processos de escolha dos livros didáticos na escola? 


\section{Desenvolvimento das reuniões}

- Como se desenvolveram essas reuniões?

- Houve acompanhamento dessas reuniões por parte da coordenação pedagógica?

- Que materiais foram utilizados para o processo de escolha dos livros? (O Guia de Livros Didáticos do MEC é utilizado?)

- Como esses materiais chegaram até a escola? (Como o Guia de Livros Didáticos chega até a escola?)

- Havia cópias desses materiais para todos os professores?

- Como esses materiais foram utilizados? (Que critérios foram sugeridos pela escola para análise dos livros?)

- Quem foi o responsável por registrar a escolha? Como ele foi escolhido?

\section{Entrega dos livros didáticos na escola}

- A escola tem recebido efetivamente os livros didáticos que foram solicitados? Em caso negativo, o que tem ocorrido?

- Houve diferenças no recebimento de livros entre as diferentes áreas disciplinares?

\section{Escolha dos livros didáticos no âmbito do PNLD/2012}

- Que mudanças, introduzidas pelo MEC, vocês percebem nesse novo processo de escolha de livros didáticos, no âmbito do PNLD/2012?

- Que ações serão organizadas pela escola para efetivar esse processo de escolha?

- Comparando com os anos anteriores, que modificações serão feitas na escola no processo de escolha de livros didáticos no âmbito do PNLD/2012? Por quê?

- Como serão organizados esses processos no âmbito do PNLD/2012? (Quem será responsável pela organização? Existem encontros previstos para realização do processo de escolha? Quantos encontros estão previstos? Quais as datas previstas para esses encontros?)

\section{Acompanhamento do processo de escolha de livros didáticos}

- A escola permitiria que integrantes do nosso grupo (Grupo de estudos, pesquisas e intervenções "Inovação Educacional, Práticas Educativas e Formação de Professores" - Inovaeduc) acompanhem o processo de escolha do livro didático, no âmbito do PNLD 2012, a ser realizado neste ano de 2011?

- A escola teria interesse em organizar um trabalho conjunto, com integrantes do nosso grupo, para desenvolver o processo de escolha do livro didático, no âmbito do PNLD 2012, a ser realizado neste ano de 2011? 